\title{
SORT as any easy technique to do; but needs more trials to be as a routine practice
}

\author{
Sarvin Sanaie ${ }^{1}$ and Ata Mahmoodpoor ${ }^{2,3^{*}}$ (])
}

Najafi has published a letter about our published article regarding the comparison of SORT maneuver versus a conventional technique of neck flexion lateral pressure (NFLP) for nasogastric tube (NGT) insertion in ICU admitted patients [1]. He mentioned that there is a lack of standard definitions for the favorable outcome like the time span attributable to "ease of insertion" and the determinants for "insertion failure". However, we tried to change the ease of insertion with our grading score which made it so easy to compare. We evaluated the ease of insertion with a 4-grade score as following: first grade as successful insertion in less than $50 \mathrm{~s}$ and in the first attempt, second grade as successful insertion in the first attempt with more than $50 \mathrm{~s}$ or in the second attempt with less than $100 \mathrm{~s}$, third grade as successful insertion in the 2nd attempt with more than $100 \mathrm{~s}$ or in three attempts, and fourth grade as failed insertion. Regarding the rate of complications, based on the incidence of each complication, we need larger sample size to show the difference in each group but considering overall complications (35\%), the mentioned sample size is sufficient to show the possible significant difference.

He also mentioned SORT maneuver as an ideal technique for NGT insertion in critically ill patients with COVID-19. As this technique considers anatomical characteristics, it can be an ideal option for health care workers who are familiar with this technique and airway anatomy. Moreover, every physician/nurses should notice the fact that NGT insertion is an aerosol producing technique and every one should consider full protection

This reply refers to the article available at https://doi.org/10.1186/s13613-02000778-1.

*Correspondence: amahmoodpoor@yahoo.com

${ }^{3}$ General ICU, Shohada Hospital, El-Goli Street, Tabriz, Iran

Full list of author information is available at the end of the article during its insertion with every technique [2]. So, SORT is an easy to learn technique; however, we should not forget the first rule in medicine: "Do not harm at first".

\begin{abstract}
Authors' contributions
AM and SS contributed equally to the drafting of manuscript and provided critical revision for important intellectual content. Both authors read and approved the final manuscript.

Funding

No.

Competing interests

The authors declare no conflict of interests.

Author details

${ }^{1}$ Neurosciences Research Center, Aging Research Institute, Tabriz University of Medical Sciences, Tabriz, Iran. ${ }^{2}$ Department of Anesthesiology and Intensive Care, Faculty of Medicine, Tabriz University of Medical Sciences, Tabriz, Iran. ${ }^{3}$ General ICU, Shohada Hospital, El-Goli Street, Tabriz, Iran.
\end{abstract}

Received: 23 October 2020 Accepted: 21 November 2020

Published online: 02 December 2020

References

1. Sanaie S, Mirzalou N, Shadvar K, Golzari SEJ, Soleimanpour H, Shamekh A, Bettampadi D, Safiri S, Mahmoodpoor A. A comparison of nasogastric tube insertion by SORT maneuver (sniffing position, NGT orientation, contralateral rotation, and twisting movement) versus neck flexion lateral pressure in critically ill patients admitted to ICU: a prospective randomized clinical trial. Ann Intensive Care. 2020;10(1):79. https://doi. org/10.1186/s13613-020-00696-2.

2. Barazzoni R, Bischoff SC, Breda J, Wickramasinghe K, Krznaric Z, Nitzan D, et al. ESPEN expert statements and practical guidance for nutritional management of individuals with SARS-CoV-2 infection. Clin Nutr. 2020;39(6):1631-8. https://doi.org/10.1016/j.clnu.2020.03.022 (Epub 2020 Mar 31).

\section{Publisher's Note}

Springer Nature remains neutral with regard to jurisdictional claims in published maps and institutional affiliations.
Springer Open

(c) The Author(s) 2020. This article is licensed under a Creative Commons Attribution 4.0 International License, which permits use, sharing, adaptation, distribution and reproduction in any medium or format, as long as you give appropriate credit to the original author(s) and the source, provide a link to the Creative Commons licence, and indicate if changes were made. The images or other third party material in this article are included in the article's Creative Commons licence, unless indicated otherwise in a credit line to the material. If material is not included in the article's Creative Commons licence and your intended use is not permitted by statutory regulation or exceeds the permitted use, you will need to obtain permission directly from the copyright holder. To view a copy of this licence, visit http://creativeco mmons.org/licenses/by/4.0/. 